\title{
ПРИМЕНЕНИЕ ТРАНСПОРТНЫХ СРЕДСТВ В ОБОЗЕ МАКЕДОНСКОЙ АРМИИ ВРЕМЕН ФИЛИППА ІІ
}

\section{THE USE OF VEHICLES IN THE BAGGAGE TRAIN OF THE MACEDONIAN ARMY OF THE ERA OF PHILIP II}

A. Kleymeonov

Summary: The problem of pack animals and wheeled wagons in baggage train using in Phillip's II army is under consideration in the article. It defends that in spite of the information from ancient author who had used Ephorus' of Cyme opus, there was no complete baggage train failure in the Macedonian army. The soldiers were really accustomed to carrying weapons and part of the field equipment by themselves and the unnecessary auxiliary personnel were removed from the army but wagons and pack animals continued to use. It was impossible to do without them when transporting the siege engines available in the Macedonian army, heavy camp equipment, provisions and trophies. The baggage train was not destroyed by Phillip but it was optimized for military needs what allowed to increase the speed of movement of troops, provided the possibility of conducting campaigns in different theaters of military operations, including those characterized by difficult terrain and a poor food base.

Keywords: Philip II, Macedonia, baggage train, wagons, infantry, siege engines, logistics.

\author{
Клейменов Александр Анатольевич \\ Д.и.н., Тульский государственный педагогический \\ университет им. Л.Н. Толстого \\ alek-klejmenov@yandex.ru
}

Аннотация: В статье рассматривается проблема применения вьючных животных и колесного транспорта в походном обозе армии Филиппа II. Определяется что, несмотря на сообщения античных авторов, восходящие к сочинению Эфора Кимского, в македонской армии не произошел полный отказ от обоза как такового. Ее представители действительно были приучены переносить вооружение и часть походного снаряжения на себе, из войска был удален излишний вспомогательный персонал, но повозки и вьючный скот продолжали использоваться. Без них нельзя было обойтись при транспортировке имевшихся в армии осадных машин, громоздкого лагерного оборудования, провианта, а также трофеев. Филипп не ликвидировал, а оптимизировал 0603 войска, благодаря чему была повышена скорость его передвижения, обеспечена возможность проведения кампаний на разных театрах военных действий, в том числе отличавшихся сложным рельефом и ограниченной продовольственной базой.

Ключевые слова: Филипп II, Македония, обоз, повозки, пехота, осадные орудия, логистика. рорыв в военном деле, совершенный в Македонии в эпоху Филиппа II и Александра Великого и приведший к масштабной экспансии, изменившей до неузнаваемости карту античной Ойкумены, попадает в поле зрения исследователей с завидной регулярностью. Однако, в сложном процессе строительства передовой македонской армии IV в. до н.э. присутствуют и слабо изученные аспекты. К последним относятся преобразования Филиппа, затронувшие обозно-транспортную систему его войска, то есть тот компонент военного механизма, который в рассматриваемую эпоху обеспечивал возможность перемещения материальных ресурсов, необходимых для поддержания боеспособности армии и, соответственно, успешного проведения кампаний.

Прямые сообщения о сути мероприятий Филиппа, коснувшихся логистической составляющей военной системы, содержатся лишь в стратегемах, вышедших из-под пера Фронтина и Полиэна. Согласно первому автору, Филипп, впервые собирая войско, запретил для всех повозки (vehiculorum usum omnibus interdixit), дозволив всадникам иметь лишь по одному обозному слуге/ носильщику (calones), а пехотинцам - по одному на деся- ток для переноски жерновов и канатов, при этом воины в походе несли на себе тридцатидневный запас муки (Front. Strat., IV, 1, 6). Полиэн упоминает, что македоняне приучались проходить по триста стадий, неся полное вооружение, а также провиант и все снаряжение, необходимое для повседневной жизни (Polyaen., IV, 2, 10). Приведенные данные, несмотря на сравнительно позднее время создания самих работ, обладают большой ценностью: между ними не только отсутствуют явные противоречия, но и имеются следы использования общего первоисточника, которым, очевидно, служил содержавшийся в сочинении Эфора Кимского рассказ о действиях Филиппа на начальном этапе его правления, то есть в 359-358 гг. до н.э. [15, с. 54-58]. Буквальная трактовка этих сообщений породила присутствующее в историографии мнение о полной ликвидации обоза в армии Филиппа [3, с. $68 ; 10$, с. $12 ; 23$, с. $31 ; 24$, с. $190-191 ; 28$, с. 146]. Тем не менее, следует заметить, что для получения оправданных выводов необходимо сопоставить приведенные сведения с информацией из других источников. Так, с сообщениями эфоровской традиции об ограничении числа сопровождавших армию лиц хорошо соотносятся данные о стремлении македонского царя не допускать 
нахождения в войске представительниц слабого пола. Согласно Афинею (XIII, 557b), Филипп не брал с собой в походы женщин, чем отличался от персидского царя, сопровождаемого наложницами. Не разрешалось привлекать спутниц и подчиненным монарха: как справедливо отметил Д. Энгельс [10, с. 12-13], присутствие этой нормы подтверждается сообщением Арриана (Anab., I, 24, 1), согласно которому Александр в первую зиму Восточного похода отправил на побывку в Македонию воинов, женившихся незадолго до начала экспедиции. О том, что привод женщин в военный лагерь считался серьезным проступком свидетельствует рассказ Полиэна об изгнании из царства двух македонских командиров, нанявших на постоялом дворе некую особу, промышлявшую игрой на псалтерии (Polyaen., IV, 2, 3). Впрочем, античная традиция содержит и ряд данных, которые аскетичному образу обоза македонской армии соответствуют хуже. Благодаря Плутарху известен эпизод, в рамках которого Филипп якобы вынужден был отказаться от лагерной стоянки в красивом месте, так как там не было травы для «подъяремных/вьючных животных» (únо孔úpıv), в итоге посетовав, что должен угождать ослам (Plut. Mor., 178a). Этот рассказ, несмотря на свой анекдотичный характер, перекликается со сведениями о прохождении кампании Александра на Балканах, состоявшейся в 335 г. до н.э., то есть всего год спустя после смерти Филиппа. Ее обстоятельства известны благодаря сочинению Арриана, рассказавшему о событиях, как полагают, либо целиком опираясь на труд Птолемея Лага [1, с. 105; 9, с. 51], либо сочетая его информацию с материалом Аристобула [13, с. 77]. В контексте рассматриваемого вопроса интересен раздел о событиях под Пелионом, где Арриан дважды упоминает, что для перевозки провианта македоняне использовали «подъяремных/вьючных животных» (úmo孔úpıa) (Arr. Anab., I, 5, 9-10), причем приводится все тот же термин, который в источниках, освещающих военную практику IV в. до н.э., по первой версии, служил для обозначения гужевых повозок [14, с. 77-78], или же, согласно другому мнению, применялся, когда речь шла и о вьючном скоте [10, с. 14].

Расплывчатый характер прямых сообщений о составе обоза македонской армии времени Филиппа II побуждает обратить внимание на имущество, которым располагало войско царя во время реальных военных кампаний, а не в учебных походах, упомянутых Фронтином и Полиэном. Прежде всего, следует упомянуть вполне обоснованное сомнение в реалистичности сообщения о переноске пехотинцами всей экипировки и месячного запаса муки, подразумевающее, что солдат должен был нести около 40 кг одного провианта, а с учетом вооружения вес его ноши мог приближаться к 60 кг [22, с. 131-132]. Кроме того, оружием и едой необходимое воину в походе имущество не ограничивалось. Большой перечень предметов, нужных пехотным подразделениям той эпохи, приводит в «Киропедии» Ксе- нофонт, отмечающий, что воинам следует брать с собой не только оружие, провиант, ручные мельницы и ремни, но и дополнительную одежду, лекарственные средства, орудия для правки копий, шанцевый инструмент, топоры, серпы, при этом автор рекомендует перевозить перечисленное на повозках (Xen. Cyrop., VI, 2, 25-37). Представленный список носит идеализированный характер, однако создавался на основании богатого опыта Ксенофонта, хорошо знавшего, от чего воины могут отказаться, а в чем возникнет нужда [19, с. 123, 215], при этом приведенный перечень имеет много точек пересечения с описанными античными авторами реалиями походной жизни воинов Александра, данными археологии и изобразительными источниками [16, с. 335-339]. За границы не только описанного в стратегемах оснащения македонян солдат, но и указанного Ксенофонтом имущества выходила и еще одна важная часть снаряжения. Речь идет о палатках, которые относительно времени правления Филиппа упоминаются лишь когда речь идет о самом монархе (Dem., XIX, 175), царевиче Александре (Plut. Alex., 9) и военачальнике Антипарте (Polyaen., IV, 4, 1), но выступают массовым явлением в Балканской кампании 335 г. до н.э.: Арриан упоминает использование македонянами набитых сеном кожаных тентов от палаток ( для пересечения Истра-Дуная (Arr. Anab., I, 3, 6), а афинский оратор Динарх говорит о «палатках варваров», куда были уведены попавшие в рабство женщины и дети из разрушенных Александром Фив (Din., I, 24). В последнем сообщении, помимо указания на походное снаряжение, затронут важный аспект македонского способа ведения войны, определявший нужду в транспортных средствах: известно, что не только при Александре, но и во времена Филиппа македоняне активно осуществляли сбор разнообразной добычи (см. Diod., XVI, 69, 7; Polyaen., IV, 2, 12; Just., IX, 2, 15-16; 3, 1-3).

Нельзя не заметить, что в войске Филиппа также имелось оборудование особого рода, обладавшее большой стратегической значимостью. Речь идет об осадных приспособлениях, появившихся в арсенале македонского царя весьма рано. Так, согласно Диодору, Филипп уже при захвате Амфиполя (357 г. до н.э.) задействовал тараны (Diod., XVI, 8, 2). Судя по данным, переданным Дедимом (D. Col., 12, 43-50), некие осадные машины были применены македонянами в 355-354 гг. до н.э. у Мефоны. Находки крупных наконечников с нанесенным на них именем Филиппа показывают, что при осаде Олинфа (348 г. до н.э.) македоняне использовали стрелометные орудия [17, с. 36; 27, с. 116-117]. В 340-е гг. до н.э. осадные машины воспринимались как характерная черта македонского способа ведения войны: об этом свидетельствуют переданный Афинеем фрагмент комедии Мнесимаха «Филипп», где македоняне хвастаются катапультами (Athen., X, 421c), а также текст «Третьей речи против Филиппа» Демосфена, согласно которому Филипп был всегда готов объявиться у городов, поставить 
машины и начать осаду (Dem., IX, 50). Богатство македонского осадного парка с опорой на сочинение Эфора описывает Диодор в рассказе об осаде Перинфа (340 г. до н.э.), где упомянуты башни высотой в восемьдесят локтей, тараны и метательные машины (Diod., XVI, 74, 3-4). Активное использование подобных приспособлений неизбежно должно было увеличить нагрузку на транспортную систему войска, так как некоторые машины перевозились в относительно готовом виде, как это было с катапультами, другие - разобранными на части, причем для подобного груза требовались повозки или морские суда $[4$, с. 71 ; 21, с. 164-165]. Кроме того, для сооружения и обслуживания осадных устройств были нужны инструменты и расходные материалы, также нуждавшиеся в транспортировке.

Основываясь на вышеизложенном, следует согласится с выводами, согласно которым в армии Филиппа вьючный скот и повозки, пусть и ограниченно, но все же должны были применятся для перевозки осадных машин, трофеев, палаток, дров и провианта, а также для санитарно-медицинских нужд [6, с. 73; 11, с. 183; 14, с. 29]. Отмеченные выше реалии македонской военной практики не позволяют присоединиться к выводам о полном отсутствии в обозе повозок, якобы заменных на вьючных лошадей [12, с. 85-86; 16, с. 330]. Тем не менее, указанные обстоятельства не означают, что описанные восходящей к Эфору традицией преобразования в области логистики не имели места в действительности или не повлияли на реальную практику. Этот блок информации описывает мероприятия первого года правления Филиппа, направленные на преодоление недостатков прежней македонской обозно-транспортной системы. Последние известны благодаря Фукидиду, упоминающему наличие в армии царя Пердикки II движимых волами повозок, перевозивших немалое количество поклажи и брошенных при поспешном отступлении (см. Thuc., IV, 128, 4). Использование этих транспортных средств, очевидно, было устойчивой традицией: как справедливо отмечено в литературе, повозки присутствовали несмотря на то, что в Линкестида, ставшая театром военных действий во время описанного Фукидидом похода, имела гористый ландшафт [18, с. 8]. Кроме того, с применением обозных повозок может быть связано и упомянутое тем же Фукидидом (Thuc., II, 100, 2) дорожное строительство, осуществленное в Македонии при царе Архелае [14, с. 28]. Филипп действительно запретил воинам пользоваться повозками для личных нужд, приучив пехоту переносить снаряжение и часть припасов на себе: эта практика не только упомянута в сообщениях Фронтина и Полиэна, но и прослеживается в полководческой деятельности Александра [16, с. 335-341; 22, с. 131-132]. Использование вьючных животных и колесного транспорта в период военных кампаний сохранилось, однако подвергалось жесткой регламентации и подразумевало, очевидно, лишь перевозку общевойскового имущества [6, с. 257].
В качестве аналогии может быть привлечен римский военный опыт позднереспубликанского и раннеимперского периодов: известно, что в результате реформ Мария в римской армии было сокращено количество обслуги, легионеры приучились носить вооружение и припасы на себе, однако в войсках использовались вьючные животные и повозки, перевозившие часть лагерного оборудования и провианта, а также осадные орудия, для которых был необходим именно колесный транспорт [26, c. 71-91].

Несмотря на то, что реальный облик походных колонн армии Филиппа не соответствовал рисуемой некоторыми исследователями аскетичности, предпринятые монархом меры принесли вполне ощутимые плоды. В частности, ограничение численности обслуги и транспорта привело к сокращению размеров маршевых колонн, которое само по себе увеличивает скорость движения войска [2, с. 380]. Филипп, судя по всему, изменил не только количество имевшихся в войске транспортных средств, но и их характер: анализ источников, освещающих завоевания Александра, показывает, что основными вьючными и тягловыми животными в обозе его армии с самого начала Восточного похода были мулы и лошади, превосходившие быков в подвижности [5, с. 73$74 ; 10$, с. 14-16]. Уменьшение количества сопровождавших войска лиц также снизило объем потребляемого продовольствия, позволяя армии дольше существовать за счет местных продовольственных ресурсов или перевозимых запасов [8, с. 27; 23, с. 31]. Новая система выгодно отличалась не только от македонского подхода к военной логистике предшествующего времени, но и от классической греческой военной практики, для которой обычным делом являлись крупные колонны, раздутые за счет многочисленного вспомогательного персонала и вьючных животных [18, с. 4-9; 20, с. 42-43; 24, с. 174-175; 25, с. 50-51]. Кроме обеспечения преимущества в подвижности над греческими противниками, изменения в обозно-транспортной системе македонской армии сделали ее более приспособленной к особенностям северобалканского театра военных действий, где гористая местность, как справедливо отметил Д. Энгельс, препятствовала широкому применению колесного транспорта [10, с. 22-23]. Другие исследователи, развивая указанный вывод, предположили, что отказ от повозок не только облегчил передвижение войска по горным дорогам, но и был полезен для экономики, так как тягловый скот оставался в стране и применялся в сельском хозяйстве [7, с. 55; 12, с. 85]. Последнее соображение сомнительно, так как Филипп, как правило, не жалел средств на военные нужды (см. Theop., FGrH 115, F225=Athen., IV, 166f; Just., IX, 8, 5-7), к тому же не смог полностью отказаться от использования вьючных животных и повозок в обозе.

Таким образом, комплексный анализ античной письменной традиции показывает, в результате реформ Фи- 
липпа II обоз македонской армии не исчез как таковой, а подвергся оптимизации. Личный состав войска был приучен переносить вооружение, часть походного снаряжения и припасов, численность вспомогательного персонала свелась к необходимому минимуму, сократилось количество вьючного и колесного транспорта, который теперь использовался лишь для перевозки имущества, имеющего особое военное значение. В результате повысилась скорость движения армии, была обеспечена возможность проведения кампаний на разных театрах военных действий, в том числе отличающихся сложным рельефом и скромными продовольственными ресурсами, что стало одной из важных слагаемых македонских военных успехов времен Филиппа и Александра.

\section{ЛИТЕРАТУРА}

1. Йорданов К. Политическите отношения между Македония и тракийските държави (359-281 пр. Хр.) (Studia Thracica 7). Coфия, 2000.

2. Клаузевиц К. О войне. М., 1998.

3. Коннолли П. Греция и Рим. Энциклопедия военной истории. М., 2000.

4. Кэмпбелл Д.Б. Искусство осады. Знаменитые штурмы и осады Античности. М., 2008.

5. Нефёдкин А.К. Конница эпохи эллинизма. СПб., 2019.

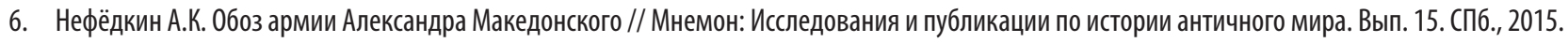
C. 248-263.

7. Уортингтон Й. Филипп Македонский. СПб. - М., 2014.

8. Ashley J.R. The Macedonian Empire: The Era of Warfare under Philip Il and Alexander the Great, $359-323$ BC. Jefferson, 1998.

9. Bosworth A.B. A Historical Commentary on Arrian's History of Alexander. Vol. I. Commentary on books I-III. Oxford, 1980.

10. Engels D.W. Alexander the Great and the Logistics of the Macedonian Army. Berkeley - Los Angeles, 1978.

11. Ferrill A. The Origins of War: from the Stone Age to Alexander the Great. Boulder, 1997.

12. Gabriel R.A. Philip II of Macedonia: Greater than Alexander. Washington, 2010.

13. Hammond N.G.L. Alexander's Campaign in Illyria // Journal of Hellenic Studies. Vol. 94. 1974. P. 66-87.

14. Hammond N.G.L. Army Transport in the Firth and Fourth Centuries // Greek, Roman, and Byzantine Studies. Vol. 24. 1983. № 1. P. $27-31$.

15. Hammond N.G.L. Training in the Use of a Sarissa and its Effect in Battle, 359-333 B. C. // Antichthon. Vol. 14. 1980. P. 53-63.

16. Karunanithy D. The Macedonian War Machine: Neglected Aspects of the Armies of Philip, Alexander and the Successors 359-281 BC. Barnsley, 2013.

17. Keyser P.T. The Use of Artillery by Philip II and Alexander the Great // Ancient World. Vol. 25. 1994. №1. P. 27-59.

18. Lazenby J.F. Logistics in Classical Greek Warfare // War in History. 1994. №1. P. 3-18.

19. Lee J.W.I. A Greek Army on the March: Soldiers and Survival in Xenophon's Anabasis. Cambridge, 2008.

20. Lee J.W.I. Daily Life in Classical Greek Armies, c. 500-330 BCE // New Approaches to Greek and Roman Warfare / Edited by L.L. Brice. Hoboken, 2020. P. 39-51.

21. Marsden E.W. Greek and Roman Artillery: Historical Development. Oxford, 1969.

22. Mattew C.A. An Invincible Beast: Understanding the Hellenistic Pike-phalanx at War. Barnsley, 2015.

23. Nawotka K. Alexander the Great. Cambridge, 2010.

24. Ober J. Hoplites and obstacles // Hoplites: The Classical Greek Battle Experience / Edited by V.D. Hanson. London - New York, 1991. P. 173-196.

25. Pritchett W.K. The Greek State at War. Part I. Berkeley - Los Angeles, 1971.

26. Roth J.P. The Logistics of the Roman Army at War (264 B.C. - A.D. 235). Leiden - Boston - Köln, 1999.

27. Snodgrass A.M. Arms and armor of the Greeks. London, 1967.

28. Strauss B.S. Alexander: The Military Campaign // Brill's companion to Alexander the Great / Edited by J. Roisman. Leiden - Boston, 2003. P. 133 -157. 